\title{
Globalización, valoración cultural Y patrimonio gastronómico.
}

\begin{abstract}
BUNUUELOS DE NAVIDAD
Se hace un batido de miga de bizcochuelo con huevos batidos, canela, vino, nuez moscada y un poco de almíbar. Aparte se dividen en cuadritos pequeños otros bizcochuelos. Se envuelven en el batido y se fríen; luego se sacan de la fritura, se envuelven de nuevo en batido y se vuelven a freir; esto se repite de la misma manera hasta que queden del tamaño que se quiera. Después de fritos todos los buñuelos se ponen a calar en almíbar sacándoles la manteca que vayan soltando por encima con una cuchara. Se sacan y se ponen a escurrir en un cedazo para servirlos con otro almíbar perfumado con vino y canela.
\end{abstract}

(Martínez: 1990)

$\mathrm{n}$ los actuales procesos de globalización cultural, económica y tecnológica, es común observar una fuerte tendencia de la industria turística a la mezcla con los avances científicos y tecnológicos. Esta previsión tecnológica que requiere el país para facilitar el acceso del turista a los diferentes productos turísticos mediante diversos sistemas de información, redefine la función de distribución y por supuesto el papel del turista como cliente. En un mundo en constante cambio, la tecnología puede garantizar la permanencia de agencias de viajes y proveedores de turismo, mediante el desarrollo e implementación de soluciones de este tipo que les permitan impulsar la distribución y comercialización de productos y servicios turísticos, a nivel nacional e internacional.

Hoy día, aunque resulte indispensable esta adición entre la industria turística y el uso de nuevas tecnologías y se haga indispensable el cierre paulatino de la brecha tecnológica, es urgente pensar en el papel del nuevo administrador turístico y hotelero quién en un futuro estará centrado no tanto en la tarea administrativa de las rutas turísticas, ni únicamente en el desarrollo de software para la distribución de los diferentes productos turísticos, sino en el contenido cultural que el reconocimiento de lugares y experiencias particulares le aportan al viajero dispuesto al reconocimiento real de contextos cargados de expresiones culturales pero también de dificultades sociales y económicas, humanizando un poco más la práctica 
turística, para consolidar el turismo social, no solamente como la extensión de viajes para aquellos que carecen de recursos sino en la búsqueda de sentidos del lugar. ${ }^{1}$

Ahora bien, el reto para el profesional del turismo y para todos aquellos que disfrutan los viajes, está fuertemente ligado con la difusión de la cultura para los primeros y con la apropiación cultural para los segundos. En primer lugar es importante tener en cuenta que la cultura junto con sus manifestaciones tradicionales se ve enfrentada a una lógica de mercado donde pierde capacidad de maniobra por su transnacionalización consolidando una amplia vitrina de productos culturales dispuestos a entrar en la lógica de circulación y consumo.

En este sentido, la descontextualización de los productos culturales que se le ofrecen al turista, son carentes de contenidos culturales e históricos desdibujando y refuncionalizando los objetos, las costumbres y la alimentación propios de cada lugar. En la medida en que se le muestra al viajero una realidad acorde a la reconciliación del atraso con la belleza, se consolida una relación que mezcla lo antiquísimo con la normalización de la sociedad. "La fascinación nostálgica por lo rustico y lo natural es una de las motivaciones mas invocadas por el turismo(...) esa industria trasnacional que es el turismo necesita preservar como museos vivientes a las comunidades arcaicas(...) Lo pintoresco, lo primitivo, pueden seducir al turista por el contraste con su vida habitual, pero mejor aun si el discurso folclórico publicitario logra convencerlo de que la pobreza no necesita ser erradicada, que las "herramientas antiquísimas" pueden llevarse bien con la cocina moderna” (García Canclini: 1995, 99).

De esta manera, los diferentes artefactos, y productos culturales como por ejemplo, las diferentes ollas de barro construidas para unos escenarios particulares, como un caserío o un poblado ahora son funcionales en los escenarios modernos como arte popular o arte kitsch, en función de una valoración de lo indígena y lo campesino descontextualizados de la riqueza de sus lugares y de las dificultades de su economía. Más allá, diferentes manifestaciones culturales que han constituido durante muchos años entramados simbólicos, se ven amenazadas por la transnacionalización de la cultura, que pone a prueba la definición de la identidad y la historia de espacios particularizados.

En segundo lugar, los viajeros se están enfrentando a fuertes cambios culturales que se producen desde su cotidianidad hasta los lugares más recónditos que visitan en búsqueda de aventuras, confort o tranquilidad. Estas transformaciones se encaminan a la mezcla de

\footnotetext{
${ }^{1}$ Es importante anotar que los sentidos del lugar, no necesariamente están dispuestos para el reconocimiento económico del administrador turístico, este no puede depender únicamente de las exigencias del mercado sino requiere con urgencia lograr autonomía frente a estas dinámicas para reflexionar lo siguiente: "dentro de la pregunta por lo particular de cada cultura, se encuentra la pregunta por los otros. Como es que lo propio del individuo humano sea introducirse en una cultura que aparece, a la vez como el límite y la condición de su existencia singular. También es posible preguntarse que constituye lo especifico de una cultura particular, considerando que, sea cual fuere el lugar que ocupa en la sociedad todos los que pertenecen a ella llevan de un modo u otro su marca.
} 
olores y sabores que destila el mundo, este lugar cuyas distancias físicas separaban las prácticas unas de otras, ahora ofrece todo el sabor del mundo desde un portal de internet, que dispone información suficiente sobre las comidas, bebidas y demás rituales en cualquier lugar del mundo, sin embargo, en la espesura del bosque se pierde el árbol, en realidad aquí no se sabe cuál es la particularidad de este olor o de este sabor, todo tiene el aroma del plástico, de la lata y del perro caliente, olores recurrentes en la cotidianidad, olores y sabores homogenizados, productos simples y reducidos que muestran la experiencia comensal como algo mecánico, desabrido y dispuesto al derrumbe estético.

Con la globalización se esperaría un fortalecimiento cultural de las experiencias y tendencias culinarias, pero paradójicamente estas manifestaciones gastronómicas bajo las dinámicas de la sobreproducción, pierden poco a poco su identidad y sus contenidos simbólicos que lo hacían merecedor para algunos casos de la categoría de patrimonio. En efecto, en esta cultura de la obsolescencia planificada y de la escasa valoración cultural se inserta la cultura culinaria, que otrora se desarrollaba al interior de los hogares y que poco a poco ha ido perdiendo protagonismo y atención, dejando escapar sus olores y sus sabores a las prisiones de los vistosos empaques de provisiones alimentarias promovidas por lo que algunos teóricos han llamado la macdonalizacion de la cultura.

El boom de las comidas rápidas es un ejemplo de imposición cultural y de diferenciación social en nuestro país, donde desplazando notablemente a comidas tradicionales como la arepa en Medellín ha logrado mutar hasta convertirse en una comida de consumo habitual llamada comida rápida paisa. "El perro caliente bomperudo agrega a la salchicha y el pan una lista infinita de combinaciones que incluyen, como punto de partida básico, ensalada de repollo y zanahoria rallados, ripio de papa frita, cebolla picada, queso pulverizado y/o mozzarella, huevito de codorniz en la corona (que puede duplicarse o triplicarse) tocineta en los intersticios, mostaza, guacamole, salsa de tomate, mayonesa, salsa rosada, aunque suene redundante, y por supuesto salsa de piña, pues ésta se ha tornado también indispensable" En el hambre de un pueblo se esconden oportunidades económicas sin antecedentes. Por lo tanto los inversionistas aguzan sus ojos, oídos y papilas gustativas. Quien domine la próxima tendencia obtendrá ganancias que, como el bomperudo parecerán no tener límites (Burgos: 2004, 46)

Otros ejemplos de esta fuerte tendencia, recurren a la distribución masiva de la comida típica, preparada con una fuerte carga de preservantes para la conservación del producto mientras que realiza el viaje a escenarios lejanos de nuestro país. Al parecer, el enlatado ha tomado la forma del turista, que con gran expectativa, esperaba sorprenderse con las experiencias vividas en otras culturas, ahora nuestro enlatado de comida típica puede viajar más que el colombiano con delirio de Marco Polo. "El sancocho, el ajiaco, el tamal, la lechona, las lentejas con salchicha y los fríjoles con pezuña salieron de la región con todo y fórmulas. Sin embargo, ya no vienen en caldero, en vasija de barro o en hojas de bijao. 
Ahora se consiguen en lata en supermercados y tiendas.(...) Ahí está el tamal tolimense (con arroz), especial (santandereano y tolimense) y paisa (sin cerdo); el ajiaco, las albóndigas y otros enlatados nacionales esperando mercado. Estos productos tienen su segmento de compradores, dice Juan Alvaro Angel, gerente de la compañía Ronda, de Bogotá. Para él, los inventarios suplen las necesidades de mujeres que trabajan, ejecutivos que viven solos y mujeres que no tienen servicio doméstico. También las compañías militares. (eltiempo.com Sección Suplementos especiales 25 de agosto de 2004)

Ese Tamal Tolimense preparado con carnes magras de Res, Pollo y Cerdo, con harina de maíz, agua, garbanzos, arvejas, zanahorias, y demás condimentos que se le adicionan, pierde toda la magia cultural, del ritual, de la receta, en este proceso de industrialización. Esta situación involucra necesariamente el debate entre los procesos de distribución del producto y la conservación de la cultura gastronómica, donde se percibe la intensión de conservar unos valores en torno a la comida colombiana. "Colombia es tierra de tamalesdice el gastrónomo Lácydes Moreno.- . Y cada pueblo tiene a orgullo proclamar que el suyo es el mejor, el más gustoso, no sin agregar que la fórmula les viene de madre a hijas, o de las abuelas, magas en las combinaciones y en el arte de doblar las hojas prodigiosas. (...) Los antioqueños obvian el arroz y privilegian el cerdo, del que son los mayores consumidores del país (...) Precisamente fue un paisa, el rionegrero Juan José Botero, el autor de A un tamal, uno de los pocos poemas- si no el único- dedicados al platillo de marras:.

Esponjado tamal, yo te saludo!.

Salve, mil veces, oloroso envuelto.

Bienvenido si traes entre tu vientre. dos grandes presas y un carnudo hueso.

Bien dije yo, tan solo masa había. donde soñé encontrar un buen relleno.

Desilusiones de la vida humana,. soñar con carne y encontrar un hueso!."2

El siguiente proyecto de investigación busca indagar, sobre la cultura alimentaria en algunas regiones de Colombia donde la CUN hace presencia con el programa de administración turística y hotelera ${ }^{3}$. Es preciso indicar que esta búsqueda se inscribe en una problemática nacional e internacional concerniente al posicionamiento de la cultura gastronómica colombiana, que en efecto, no ha logrado un total reconocimiento de su diversidad alimentaria e imposibilita la consolidación de un sin número de productos como patrimonio alimentario de la Nación, debido en gran medida a la diversidad cultural en la

\footnotetext{
2 Tomado de el tiempo eltiempo.com sección nación fecha de publicación 23 de junio de 2002bernardo bejarano g. * redactor de Bernardo bejarano g. ${ }^{*}$ redactor de el tiempo

${ }^{3}$ Estos lugares son: Cartagena, Santa Marta, Montería, Bogotá.
} 
preparación y utilización de ingredientes que manejan las distintas culturas populares de cada región.

En este sentido, se hace necesario un examen minucioso sobre las recetas y productos típicos de las regiones antes mencionadas, donde la cultura popular las mantiene bajo una tradición oral. Por este motivo, esta investigación se centra en la cultura alimentaria de estos lugares, privilegiando la historia oral como estrategia metodológica para la recuperación de la memoria colectiva, que desde una cultura popular consolidan en la vida cotidiana este entramado de prácticas, conocimientos, creencias, valores y saberes en torno a los alimentos, para fortalecer las ideas sobre lo que es consumible, lo que es sabroso y demás criterios estéticos que permiten percibir lo agradable y lo desagradable de los platos de estos lugares, de esta manera, se ubicaran productos y recetas que consolidan, de acuerdo a valores, creencias y significados una cultura gastronómica capaz de representar a estas sociedades en específico.

Una vez indagada en una primera fase de la investigación, estas prácticas alimentarias a través de sus recetas y productos típicos, se pasara a una segunda fase para la promoción de dichos productos con un aporte al posicionamiento de una cultura gastronómica colombiana. Dicha promoción se realizara vinculando las practicas del emprendimiento, que se constituye en la impronta de la corporación, en realidad lo que se busca es el desarrollo de ofertas especializadas y diferenciadas de productos gastronómicos, que sean competitivos en el sector turístico.

La siguiente investigación pretende constituir su objeto de estudio a partir de la cultura alimentaria que se construye a partir de las culturas populares de los siguientes lugares de Colombia: Cartagena, Santa Marta, Montería, Bogotá. En este sentido, la cultura alimentaria estaría inserta dentro de unas dinámicas socioeconómicas, socioculturales y sociotécnicas que consolidan categorías más o menos rígidas de la sociedad en cuanto a patrones alimenticios. Así la cultura alimentaria incluiría los productos y sus técnicas de producción o elaboración y también valores, creencias, usos, costumbres y formas de consumo que se le asociaran (Espeitx, 2004, 195) sin embargo, la cultura alimentaria no es posible estudiarla al margen del turismo, en la medida en que esta es susceptible de consolidarse como patrimonio gastronómico que permite, en palabras de García Canclini, invocar la fascinación nostálgica por lo rustico y lo natural, motivación singular del turismo.

De esta manera , "La globalización de la gastronomía tiene una gran base en la revolución informática que permite acceder fácilmente a otras culturas generando transformaciones a nivel socioeconómico en diferentes países, cambiando de una estructura económica agroexportadora a una agroindustrial con claro predominio de las actividades propias del sector terciario de la economía.(...) La Gastronomía ha sufrido grandes cambios en los 
últimos años a nivel mundial fusionando la diversidad de sabores y aromas para crear nuevos hábitos alimenticios y una amplia oferta de platos que permiten trascender las barreras de lo tradicional, permitiendo así un potencial auge de cocineros que han subido de nivel para dar paso a profesionales cada día más preparados y dispuestos a incursionar en sus raíces culturales; a fin de experimentar nuevas recetas que parten del profundo conocimiento de las materias primas aunadas a una alimentación balanceada cumpliendo con estándares de calidad.( PROYECTO ALIMENTOS Y BEBIDAS CUN)

No obstante, el proceso de globalización es paradójico, "en cierto sentido, abren al individuo a la presencia de los demás; corresponden a una circulación más fácil de los seres, de las cosas y de las imágenes. Pero, en otro sentido, dichas figuras repliegan al individuo sobre sí mismo, haciendo de él más un testigo que un autor de la vida contemporánea" (Auge: 2000:105). En esta complejidad, se inscribe la cultura alimentaria que puede llegar a mezclarse con otras tendencias, pero también puede llegar a reforzar su carácter local como centro de gestión de lo global. En efecto, "la articulación entre empresas privadas y gobiernos locales, en el marco de relaciones globales, reguladas por negociación entre Estados Nacionales, es la trama institucional y organizativa fundamental de los procesos de creación de riqueza" (Castells, 2000, 15)

En este orden de ideas la actividad turística en Colombia poco a poco se consolida como una fuente importante de ingresos económicos generando un verdadero impacto en el PIB, en la medida en que se han superado los problemas de inseguridad que imposibilitaba la visita y la permanencia del turista en el país. De esta manera, la actividad turística en los próximos diez años, según la visión del Ministerio de Comercio Industria y Turismo, estará dirigida al fortalecimiento de la competitividad regional y la especialización de productos culturales muy específicos, que permitan posicionar al país desde el escenario local e internacional.

"Para el 2020 Colombia habrá posicionado la actividad turística como una de las de mayor importancia para el desarrollo económico del país (...) en este orden de ideas Colombia habrá definido unos productos básicos en los que recogerá toda su oferta turística nacional. Las regiones se habrán especializado en ofertas diferenciadas y los municipios se habrán comprometido en programas de mejoramiento en diferentes frentes teniendo como objetivo la competitividad de su producto turístico."

En definitiva, es así, como la cultura alimentaria inserta en complejos procesos de globalización cultural y económica, se fortalece en el plano local, dentro de un proceso

\footnotetext{
${ }^{4}$ Ministerio de comercio, industria y turismo, vice ministerio de turismo, política nacional de turismo. Plan sectorial de turismo 2008- 2010 “ Colombia, destino turístico de la clase mundial mayo 2008
} 
global, permitiendo el fortalecimiento de tradiciones y de culturas populares para consolidar unos saberes, creencias y valores susceptibles de ser rastreados para la consolidación de una cultura gastronómica en Colombia que sea competitiva en el ámbito mundial.

\section{Referencias}

Augé M, (2008) el viaje imposible el turismo y sus imágenes editorial Gedisa, Barcelona España

Cartay R. (1996) aproximaciones a la historia de la gastronomía andina consultado en http://iies.faces.ula.ve/Revista/Articulos/Revista_11/rev11cartay.htm

Diaz E. 1985 Quehaceres de doña Agustina. En novelas y cuadro de costumbres tomo II. Nueva biblioteca colombiana de cultura

Diaz L (2003) La cocina del barroco: la Gastronomía del Siglo de Oro en Lope, Cervantes y Quevedo, Alianza editorial

DTS Consultores. (2007). Identificación y puesta en valor de rutas turísticas para la región de Coquimbo. Turismo, Sostenibilidad, Proyectos. Recuperado de: http://astroturismochile.cl/wp-content/uploads/2015/01/Identificaci\%C3\%B3n-y-puesta-envalor-de-rutas-tur\%C3\%ADsticas-para-la-Regi\%C3\%B3n-de-Coquimbo-2007-DTSConsultores.pdf

Espeitx E. (2004) Patrimonio alimentario y turismo: una relación singular. En: pasos revista de turismo y patrimonio cultural, volumen 2 numero 2. pág. 195

Espeitx E. (2011) Sabores culturales: ensayos sobre alimentación y cultura / Elena Espeitx Bernat, Juanjo Cáceres Nevot ; prólogo de F. Xavier Medina ; Helena Amigo Gómez ... [et al.]. Mataró] : Montesinos : Unión Europea, 285 p.

Geertz, C. [1996]. "Descripción densa: hacia una teoría interpretativa de la cultura”. En: La interpretación de las culturas. Barcelona. Editorial Gedisa. 
Groot Ana María. (2004) Arqueología y Patrimonio: conocimiento y apropiación social. En: Revista Académica Colombiana de ciencia (30)5-17 2006 ISSN 0370-3908.

Llano et al (2014) Lo que no se narra se olvida, recuperación de la cocina tradicional en Cundinamarca y Boyacá. Editorial Sena

Llano, F. 2013. Turistas comensales. Patrimonio gastronómico y turismo alimentario en Nemocón y Ubaté. ISBN 978-958-8191-34-8. Corporación Unificada Nacional de Educación Superior CUN

Martínez Carreño A, 1985 mesa y cocina en el siglo XIX. Fondo cultural cafetero.

Mejía Escobar, Alicia. (2011) Evaluación de la Gastronomía Colombiana como factor potencial de turismo. Fondo de promoción turística Colombia. Ministerio de Comercio Industria y Turismo.

Orjuela Quintero Luis Antonio. 1999 Nemocón: sal y cultura. Breves apuntes para su monografía. Talleres gráficos de impresos calidad.

Palacios C. (2010) Turismo y memoria. Reflexiones teórico metodológico sobre el Espacio para la Memoria - Buenos Aires, Argentina Estudios y Perspectivas en Turismo, vol. 19, núm. 2, marzo, 2010, pp. 268-278 Centro de Investigaciones y Estudios Turísticos Buenos Aires, Argentina

Rosana Guevara Ramos, Sergio Molina y Jordi Tresserras (2006) hacia un estado de la cuestión en investigación turística estudios multidisciplinarios en turismo Volumen 1, Secretaría de Turismo Centro de Estudios Superiores en Turismo Red de Investigadores y Centros de $\begin{array}{llll}\text { Investigación } & \text { en } & \text { Turismo } & \text { tomado }\end{array}$ http://bibliotecas.umar.mx/publicaciones/Estudios_versi\%C3\%B3n\%20electr\%C3\%B3nica .pdf\#page $=18$ 
Sustaita A. (2008) La puerta y el espejo: el doble en Escher y Borges Extravío. Revista electrónica de literatura comparada 3 (2008) ISSN: 1886-4902<http://www.uv.es/extravio>

Velez L. (2010) Tres herencias gastronómicas. De África: boca’o bueno, boca’o malo. Magia y alimentación en el pacífico colombiano. CD Todos somos Colombia.

Vergara A. (2013) Etnografía de los lugares, una guía antropológica para estudiar su concreta complejidad, escuela Nacional de Antropología e Historia, ediciones Navarra, México 